\title{
O conteúdo "lutas" nas aulas de educação física em escolas do Oeste do Paraná1
}

\section{The thematic unit "martial arts" in physical education classes in schools in Western Paraná}

\section{Las lucha de contenidos en las clases de educación física en las escuelas del Oeste de Paraná}

\author{
iD (9) Andreia Cristine Becker \\ Universidade Estadual do Oeste do Paraná (Unioeste), Marechal Cândido Rondon, \\ Paraná, Brasil \\ e-mail: deia.judoca@hotmail.com \\ iD Gabriela Simone Harnisch \\ Universidade Estadual do Oeste do Paraná (Unioeste), Marechal Cândido Rondon, \\ Paraná, Brasil \\ e-mail: agaby_@hotmail.com \\ iD) Gustavo André Borges \\ Universidade Estadual do Oeste do Paraná (Unioeste), Marechal Cândido Rondon, \\ Paraná, Brasil \\ e-mail: gustavo.borges@unioeste.br
}

\begin{abstract}
Resumo: O objetivo deste artigo foi verificar se os professores de Educação Física desenvolvem o tema "lutas" em suas aulas. Participaram do estudo oito professores de Educação Física de escolas públicas da microrregião oeste do estado do Paraná - Brasil. Foi utilizada uma entrevista semiestruturada e os dados foram tratados segundo a análise do conteúdo. Como resultados, verificamos que os professores desenvolvem o conteúdo "lutas" insuficientemente, utilizam apenas as atividades que dominam, são dependentes de materiais de apoio e, geralmente, ministram aulas teóricas ou realizam visitas com seus alunos às academias e trazem professores convidados. Concluímos que o tema "lutas" é
\end{abstract}

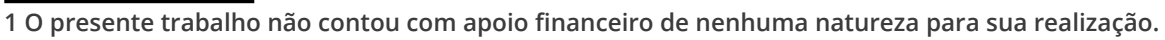


pouco trabalhado em razão da formação inicial insuficiente, bem como necessita-se de uma formação continuada para essa abordagem.

Palavras-chave: Docentes. Educação Física. Ensino. Esporte de combate.

Abstract: The objective was to verify if physical education teachers develop the theme "fights" in physical education classes. Eight Physical Education teachers from public schools in the western micro-region of the state of Paraná - Brazil participated in the study. A semi-structured interview was used, and the data were treated according to the content analysis. As a result, teachers develop the content " fights "insufficiently, developing only the activities they know, are dependent on support materials and teach theoretical classes or make visits with their students to the academies or bring in invited teachers. We conclude that the theme "fights" is little discussed, due to its insufficient initial training, as well as needing continued training for this thematization.

Keywords: Teachers. Physical Education. Elementary School. Combat sport.

Resumen: El objetivo fue verificar si los profesores de educación física desarrollan el tema "luchas" en las clases de educación física. En el estudio participaron ocho profesores de Educación Física de escuelas públicas de la microrregión occidental del estado de Paraná - Brasil. Se utilizó una entrevista semiestructurada y los datos se trataron según el análisis de contenido. Como resultado, los docentes desarrollan los contenidos "luchas" de manera insuficiente, desarrollando solo las actividades que conocen, dependen de materiales de apoyo y generalmente imparten clases teóricas o realizan visitas con sus alumnos a las academias o traen profesores invitados. Concluimos que el tema "luchas" es poco discutido, por su insuficiente formación inicial, además de necesitar formación continua para esta tematización.

Palabras clave: Maestros. Educación Física. Enseñando. Deporte de combate.

Submetido em: 18-03-2021

Aceito em: 27-07-2021 


\section{Introdução}

As "lutas", enquanto atividade física, estão inseridas em vários contextos culturais. Elas estão presentes na sociedade como artes marciais e/ou esportes de combate, tanto nos treinamentos de segurança (na segurança pública e na privada), exercícios militares, quanto nos clubes e academias (enquanto modalidades esportivas institucionalizadas), carregando consigo sua história, sua origem, sua vestimenta, suas tradições e características que competem a cada manifestação de luta (GOMES et al., 2010). As "lutas" ainda são timidamente ensinadas nas escolas, enquanto parte da cultura de movimento nas aulas de educação física (BOEHL, 2018).

As "lutas", a partir de suas características e aproximações, são

consideradas como uma "prática corporal imprevisível, caracterizada por determinado estado de contato, que possibilita a duas ou mais pessoas se enfrentarem numa constante troca de ações ofensivas e/ou defensivas, regida por regras, com o objetivo mútuo sobre um alvo móvel personificado no oponente" (GOMES et al., 2010, p. 221).

O nível de contato entre os praticantes varia de acordo com os objetivos de cada modalidade e distância de realização das ações, sendo classificadas como "lutas" de curta, média e longa distância, mas há também as "lutas" mistas (GOMES et al., 2010; RUFINO; DARIDO, 2015).

Para a temática "lutas" ser inserida nas aulas de Educação Física no Estado do Paraná, as Diretrizes Curriculares recomendam que as modalidades esportivas de combate devem ser desmistificadas como apenas um confronto entre duas pessoas num formato de "briga" (socos e pontapés), reforçando atitudes agressivas, bem como devem ser abordadas sem a dependência de espaços, materiais e vestimentas específicas para que todos os estudantes possam vivenciá-las de forma crítica e consciente (PARANÁ, 2008). 
O conteúdo lutas nas aulas de educação física em escolas do Oeste do Paranaense Andreia Cristine Becker • Gabriela Simone Harnisch • Gustavo André Borges

Nesse sentido, o ensino das "lutas" está mais aberto, de forma que podem contribuir tanto com a formação dos professores quanto dos alunos (HARNISCH et al., 2018).

Barbosa do Nascimento e Almeida (2007) avaliaram que na percepção dos alunos, as "lutas" carregam uma grande dose de preconceito quando tematizadas nas aulas, atribuindo-lhes o imaginário de esportes violentos. Isto é, existe ainda certo preconceito em relação às práticas das "lutas" pelo fato de, no senso comum, as pessoas associarem as mesmas a uma manifestação corporal violenta. Porém, é importante salientar que as "lutas", enquanto esporte de combate, despertam valores sociais e humanos para muito além disso.

Nesse sentido, como conteúdo das aulas de educação física, os alunos precisam conhecer e aprender as diferentes habilidades e capacidades motoras envolvidas nas "lutas", o seu conhecimento histórico e os seus valores éticos e estéticos. Na escola, uma das maiores dificuldades para o ensino das "lutas" é, para muitos professores, a falta de espaços e materiais adequados; a desmistificação de paradigmas ainda vigentes acerca de crenças e concepções; as lacunas nos currículos de formação de professores de Educação Física, com poucas oportunidades de formação continuada sobre o tema, que geram insegurança nos professores para ministrar aulas voltadas às «lutas» (FONSECA et al., 2013; MATOS et al., 2015; RUFINO, 2016). Santos e Brandão (2018) identificaram que os professores tiveram pouco contato e de forma muito fragmentada com esportes de "lutas", como o judô, caratê, boxe e a capoeira, repercutindo em pouco domínio dos elementos básicos dessas práticas corporais e desenvolvimento desses conteúdos na escola.

Tanto o conteúdo "lutas" quanto os demais temas das aulas de educação física não devem ser trabalhados somente como uma prática a ser reproduzida, com um fim nela mesma, mas também como reflexão de sua origem e inserção na sociedade e suas contribuições para vários aspectos da formação humana, que vão além do aspecto meramente motor de uma prática esportiva. A 
O conteúdo lutas nas aulas de educação física em escolas do Oeste do Paranaense Andreia Cristine Becker • Gabriela Simone Harnisch • Gustavo André Borges

sua contribuição é tão relevante para a cultura de movimento que esse conteúdo está amplamente refletido no principal documento que norteia atualmente a Educação Física no Brasil, a Base Nacional Comum Curricular (BNCC, 2018).

Mesmo sendo um documento normativo e não obrigatório, a BNCC passa a tratar do tema "lutas" com relevância, pois amplia a compreensão das suas diferentes formas de expressão cultural, por exemplo, do comunitário e regional (como a capoeira, luta marajoara, indígenas etc.) ao universal (muay thai, boxe, esgrima, taekwondo, judô, caratê etc.), além de propor uma forma da sua classificação (curta, média e longa distância), para ajudar no planejamento das aulas, no sentido de abordar as "lutas" de forma que envolva modalidades diferentes, mas que possuem características semelhantes (BREDA et al., 2010).

Segundo Alencar et al. (2015), não está sendo oportunizada nas aulas de educação física a possibilidade de vivenciar todas as dimensões da cultura de movimento. Ou seja, há uma grande resistência quanto à abordagem do conteúdo "lutas" nas aulas e, infelizmente, isso tem sido pouco explorado no âmbito escolar, tanto na sua aplicação como na seleção dos temas. É de fundamental importância que as "lutas" sejam trabalhadas nas escolas para que elas possam contribuir de forma efetiva na construção da cultura de movimento.

Esses estudos demonstram como é difícil para os professores desenvolverem o conteúdo "lutas" nas aulas, mesmo tendo uma formação para isso na sua graduação. Além disso, no estado do Paraná, através das suas Diretrizes Curriculares Estaduais (PARANÁ, 2008), essa temática se tornou obrigatória, sendo preciso, portanto, compreender como os professores estão desenvolvendo-a em suas aulas. Assim, o objetivo deste estudo foi identificar se os professores de Educação Física desenvolvem o conteúdo "lutas" nas aulas de educação física nas escolas da microrregião do Oeste do Paraná. 


\section{Métodos}

Este estudo caracterizou-se como uma pesquisa descritiva, com uma abordagem qualitativa dos dados. A amostra foi composta por oito professores de Educação Física que ministram aulas no ensino fundamental do $6^{\circ}$ ao $9^{\circ}$ ano em escolas públicas da microrregião oeste do Paraná, nas cidades de Quatro Pontes, Marechal Cândido Rondon, Mercedes, Pato Bragado, Entre Rios do Oeste e Nova Santa Rosa. Os professores foram selecionados por conveniência, pois aceitaram participar do estudo. Esta pesquisa foi aprovada no Comitê de Ética em Pesquisa com Seres Humanos da Universidade Estadual do Oeste do Paraná (CAAE Nº 94212218.2.0000.0107), sob o Parecer N².858.042.

O instrumento utilizado para a coleta de dados foi uma entrevista semiestruturada elaborada pelos pesquisadores para uso exclusivo nesta pesquisa. A entrevista se constituiu em uma técnica de interação social, sob a forma de diálogo assimétrico (GERHARDT; SILVEIRA, 2009). O registro da entrevista ocorreu por meio de um gravador de voz, da marca SIXER, modelo SX-198GD.

A análise dos dados foi realizada por meio de análise de conteúdo, conforme recomendação de Bardin (1995). A análise das respostas ocorreu em três etapas, sendo realizada inicialmente uma "leitura flutuante", buscando classificar e apresentar as respostas mais relevantes entre todos os entrevistados. Em seguida, foram selecionadas as palavras, termos, números, sentenças e/ou frases que objetivamente responderam e foram consideradas as mais significativas ao tema abordado.

Após serem realizadas as etapas anteriores do procedimento da análise das informações, a última etapa foi interpretar as respostas, expondo as "categorias" emergentes, das quais foram efetivamente consideradas. Ou seja, as categorias das respostas analisadas surgiram procurando obedecer a "pertinência" aos objetivos do estudo, sendo apresentados para a análise final os 
O conteúdo lutas nas aulas de educação física em escolas do Oeste do Paranaense Andreia Cristine Becker • Gabriela Simone Harnisch • Gustavo André Borges

exemplos/citações mais importantes obtidos a partir das respostas dos professores entrevistados.

\section{Resultados e discussão}

Os professores entrevistados apresentavam idades entre $38 \mathrm{e}$ 57 anos (44,8 86,4 anos) e todos são formados em Licenciatura em Educação Física em uma instituição pública. O tempo de formação médio dos participantes investigados foi de 21 anos e uma média de 19 anos no magistério.

Em relação ao número de instituições escolares em que os professores trabalham, a maioria deles atua em pelo menos dois estabelecimentos distintos, enquanto apenas dois disseram atuar em apenas uma escola. Em relação à realização de formação continuada, após a formação inicial em Educação Física, cinco professores possuem algum tipo de curso de especialização. Os professores também disseram participar de cursos de formação continuada, geralmente abaixo de 20h, ofertados anualmente pela Secretaria de Educação do Estado do Paraná ou ofertados em eventos da área pelas instituições universitárias regionais.

Com relação à categoria formação, para a disciplina de "lutas"/ esportes de combate durante a sua graduação, todos os professores afirmaram que tiveram formação acadêmica apenas em artes marciais, sendo a disciplina de judô a mais prevalente. Além do judô, alguns deles afirmaram que tiveram também a capoeira, enquanto outros afirmaram que tiveram um contato superficial com o boxe, como temas pontuais. Todas essas outras manifestações das "lutas"/esportes de combate ocorreram de forma isolada durante a disciplina de judô e com professores/mestres convidados para essas aulas específicas, sendo que todos avaliaram que esses conteúdos não foram suficientes para o aprendizado dessas atividades e, portanto, também não os qualificaram para darem aulas com essa temática. 
O conteúdo lutas nas aulas de educação física em escolas do Oeste do Paranaense Andreia Cristine Becker • Gabriela Simone Harnisch • Gustavo André Borges

É importante ressaltar que em instituições públicas os cursos mais antigos não tinham como requisito desenvolver a disciplina de "lutas", mas sim desenvolver alguma arte marcial específica, por sua inserção esportiva, como o judô, que é a disciplina mais tradicional ofertada na formação em educação física (ANTUNES, 2009). Acerca de tal achado fica evidente que há a necessidade de repensar os currículos de formação inicial superior, bem como de oferecer possibilidades de formação continuada de forma específica sobre as "lutas" para os professores da educação básica, já que os professores têm demonstrado sentir-se inseguros para ministrar esse conteúdo (FONSECA et al., 2013; RUFINO, 2016).

Assim, pode-se afirmar que a formação do professor é de extrema importância e muitas dificuldades do ensino das "lutas" nas escolas é justamente pelo fato dos professores não terem em seus cursos a formação necessária para ensinar esse conteúdo. Em alguns casos não há de fato a presença das "lutas" no currículo dos cursos e, quando existe, é restrita a somente uma modalidade, dificultando assim o seu ensino nas escolas (DEL VECCHIO et al. apud RUFINO; DARIDO, 2015). Corroborando essa ideia, Ferreira (2006) buscou compreender como os professores de Educação Física das escolas de Fortaleza (CE) utilizavam o conteúdo "lutas" e verificou que $68 \%$ afirmaram que jamais utilizaram esse conteúdo em suas aulas.

Sobre a participação dos professores em projetos universitários durante a sua formação, relacionados ao conteúdo de "lutas"/ esportes de combate, todos os professores afirmaram não terem participado de projetos com esse conteúdo. Isto é, a experiência com o conteúdo e o ensino das "lutas"/esportes de combate, durante a sua formação universitária, se restringiu, quase que exclusivamente, com a arte marcial judô, em uma disciplina ofertada no curso. Hegele et al. (2018) desenvolveram uma pesquisa-ação com professores de Educação Física visando, por meio de um curso de extensão, proporcionar conhecimentos sobre as "lutas" e perceberam que com o estudo relacionado aos jogos de "lutas" e de sua classificação com base nas distâncias, a produção de tarefas 
O conteúdo lutas nas aulas de educação física em escolas do Oeste do Paranaense Andreia Cristine Becker • Gabriela Simone Harnisch • Gustavo André Borges

e a vivência corporal durante os encontros permitiu entender que é possível o ensino das "lutas" na escola sem ter uma experiência como lutador em um esporte de combate específico, comprovando a relevância das atividades de extensão para a ampliação do conhecimento dos professores.

$\mathrm{Na}$ escola, os procedimentos para a inserção das "lutas" têm sido observados desde a década de 1990; preocupações têm sido gerenciadas com o objetivo de inserir, de fato, a luta como conteúdo da educação física escolar. As "lutas"/artes marciais são de fundamental importância no contexto cultural e motor, porém é preciso pensar na formação profissional para que seja possível haver uma melhor intervenção desse conteúdo, ou seja, não é interessante aplicar somente a prática isolada de algumas modalidades nas aulas de «lutas»/artes marciais. Deve se pensar em abordar as «lutas» a partir de aproximações e aspectos universais, com a questão de conceitos, procedimentos e atitudes que os auxiliem a observar, analisar e avaliar melhor esse tipo de prática corporal, compreendendo, assim, os processos envolvidos em sua aprendizagem para que assimilem os conteúdos e aprendam a ensinar e não somente a executar técnicas (DEL VECCHIO; FRANCHINI, 2006; HEGELE et al., 2018).

Quando os professores foram questionados se consideram importante o conteúdo "lutas" para as aulas de educação física no ensino fundamental, todos responderam de maneira positiva, mas as razões para a sua importância foram bem diversificadas. Por exemplo, para os professores, a categoria violência foi apontada por eles sobre como os alunos percebem o conteúdo "lutas", indicando, portanto, que a inclusão desse conteúdo precisa ser feita nas aulas para "desmistificar" essa percepção entre os estudantes. Um dos professores reforçou em sua fala a ideia de que os alunos precisam entender que as "lutas" não são atividades sem regra e sem fundamento, como "brigas", trazendo um "diferencial que é a questão do autocontrole e eles saberem respeitar regras" professor número 5. 
O conteúdo lutas nas aulas de educação física em escolas do Oeste do Paranaense Andreia Cristine Becker • Gabriela Simone Harnisch • Gustavo André Borges

Outro professor considera as "lutas" como "atividades diferentes" das modalidades que normalmente são aplicadas e então os alunos querem participar o professor número 4. Houve aqueles que afirmaram ainda que as "lutas" são temas obrigatórios por fazerem parte das DCE (2008), portanto devem ser ministradas por força da Diretriz. Por fim, como razão da sua importância, outro professor afirmou que o conteúdo "lutas" desenvolve "confiança e responsabilidade dos alunos" professor número 3, sendo uma das razões para desenvolvê-las em suas aulas. Podemos perceber uma preocupação com as possibilidades educacionais do ensino das "lutas", sobretudo as artes marciais, que embutem valores como cultura, disciplina e respeito. É possível observar a importância de utilizar as "lutas" para se trabalhar e promover questões e valores como respeito e autoconfiança.

O professor de Educação Física é responsável por proporcionar novas vivências aos seus alunos em outras formas de "lutas"/ esportes de combate, fazendo com que eles questionem e façam reflexões críticas. Nessa direção, Breda et al. (2010) defendem que é um momento oportuno para apresentar o tema "lutas"/esportes de combate para desenvolver a personalidade das crianças e adolescentes, através da cooperação, participação, convivência, emancipação e coeducação. É preciso que não haja somente a transferência de conhecimento técnico esportivo, mas também de valores culturais relacionados à modalidade para que, dessa forma, seja possível obter um crescimento verdadeiro (BREDA et al., 2010).

Para Lançanova (2007), o ensino das "lutas" também oferece um conjunto de temas e oportunidades que auxiliam no desenvolvimento integral do professor. Se o seu potencial pedagógico for considerado, as "lutas" se tornam um instrumento de grande valor, por ter uma ação corporal exclusiva e uma natureza histórica, e principalmente pelo rico acervo cultural que as "lutas" trazem dos seus povos de origem. Nesse caso, tanto professores quanto alunos se beneficiariam do envolvimento, pedagogicamente adequado, das "lutas" nas aulas. 
O conteúdo lutas nas aulas de educação física em escolas do Oeste do Paranaense Andreia Cristine Becker • Gabriela Simone Harnisch • Gustavo André Borges

Apesar de os professores listarem vários aspectos importantes do ensino das "lutas", apenas cinco deles responderam que desenvolvem essa unidade temática, enquanto os demais, apesar de entenderam que são importantes, não a desenvolvem. Um dos professores que não desenvolvem o conteúdo de "lutas", mas o consideram importante, justifica que desenvolve a "parte motora" o professor número 6 e ainda o respeito e a consciência do corpo em outros temas de suas aulas, enquanto outro afirma ser importante que os alunos "tenham uma noção das "lutas" existentes" o professor número 8, mas não soube dizer como isso deveria acontecer. Um deles não justificou a razão por não desenvolver esse conteúdo.

Daqueles professores que desenvolvem o conteúdo "lutas" em suas aulas, quando questionados sobre como planejam e como são distribuídas essas aulas, apenas três afirmaram que o conteúdo "lutas" é distribuído através de aulas em um dos trimestres. Para um deles, o conteúdo é planejado com o tema judô, enquanto os demais planejam e realizam pesquisas sobre capoeira e temas pré-determinados, mas não ministram aulas práticas sobre "lutas"/esportes de combate.

Sobre os temas específicos que os docentes planejam, os dois professores que desenvolvem modalidades específicas, como judô e capoeira, disseram desenvolver esses temas de forma lúdica. Outro professor relatou que aproveita a experiência e conhecimento dos seus alunos em alguma modalidade esportiva das artes marciais para utilizá-los em suas aulas. Apenas um dos professores afirmou realizar aulas apenas teóricas: “[...] no meu planejamento, eu fiz muito mais parte teórica do que prática, mesmo" o professor número 4.

Em relação às metodologias e estratégias que os professores utilizam para desenvolver o conteúdo de "lutas", a maioria deles respondeu que utiliza diversas estratégias, não se fixando em uma única apenas. Por exemplo, $40 \%$ das respostas apontaram para "aulas teóricas", que também podem ser ministradas por outros profissionais do esporte estudado, ou aulas práticas com "temas 
O conteúdo lutas nas aulas de educação física em escolas do Oeste do Paranaense Andreia Cristine Becker • Gabriela Simone Harnisch • Gustavo André Borges

específicos" (30\%). Apenas um professor admitiu desenvolver o conteúdo "lutas" de forma lúdica, como estratégia de ensino. "[...] aproveito o que tem na cidade de modalidades (de "lutas")" o professor número 2. "[...] trazer outros profissionais para aprimorar" o professor número 3.

Nesse sentido, o que é explicitado por Gomes et al. (2010), Gonzáles et al. (2014), Rufino e Darido (2015a; 2015b), Hagele et al. (2018) acerca das práticas pedagógicas para o ensino das "lutas" torna-se evidente, de modo que, ao desenvolver o conteúdo a partir de conhecimentos referentes às suas classificações (curta, média e longa distância) pautadas em princípios condicionais (contato proposital, fusão ataque/defesa, imprevisibilidade, oponente/ alvo e regras), com abordagens lúdicas e por meio do jogo, as "lutas" passam a ser uma possibilidade para aqueles professores que não apresentam conhecimentos aprofundados em modalidades específicas, tendo condições de analisar, refletir e adaptar maneiras para que os alunos tenham acesso a essa forma de manifestação da cultura corporal de movimento.

Contrapondo os autores, outra maneira de desenvolver o conteúdo na escola, na concepção de Lançanova (2007), traduz-se em uma demonstração de várias modalidades de "lutas" aos alunos como "opções" para que estes possam optar pela modalidade esportiva que desejam praticar, fora da escola. Assim, para esse autor, o professor não necessita ser formado em uma luta específica, pois pode facilmente usar outros recursos, como aulas em academias ou até utilizar vídeos, porém o trabalho do professor de educação física vai além de ensinar ou promover a iniciação em uma modalidade esportiva de combate, mas que ensine um conteúdo que lhe sirva para a vida.

Quando os professores foram questionados sobre a percepção e aceitação dos alunos quanto ao desenvolvimento desse conteúdo, os resultados foram muito distintos. Por exemplo, alguns professores afirmaram que há uma boa aceitação do conteúdo de "lutas", mas que, apesar disso, alguns alunos ou turmas gostam mais, além daqueles que são mais tímidos que os demais. Para 
O conteúdo lutas nas aulas de educação física em escolas do Oeste do Paranaense Andreia Cristine Becker • Gabriela Simone Harnisch • Gustavo André Borges

outro professor, a aceitação aumenta se a aula for prática, pois conclui que: "[...] eles gostam, não há tanta rejeição, na verdade, eles queriam prática" o professor número 7.

Para um dos professores o professor número 2, a experiência do ensino de "lutas" demonstrou que houve uma rejeição inicial dos alunos, talvez pelo costume deles em terem aulas práticas de outros esportes, mas, para o mesmo professor, isso também depende da metodologia empregada para a aceitação dos alunos. Outro professor afirmou que há sempre maior rejeição por parte das meninas, pois relata que "os alunos acham muito que "lutas" é briga, que eles vão aprender uma 'coisa', que vão poder brigar" o professor número 4, inibindo, neste caso, a participação efetiva feminina.

Ao serem questionados se houve mudança de comportamento por parte dos alunos, após o desenvolvimento de aulas voltadas ao conteúdo de "lutas", quatro afirmam que sim, que é possível perceber uma mudança de comportamento, embora um deles afirme que é difícil perceber algo específico. Aqueles que perceberam alguma mudança de comportamento dos seus alunos apontaram que, além de haver maior interesse pela disciplina, os alunos apresentaram maior concentração e respeito com o próprio professor e com os colegas. Também surgiu nas respostas que os alunos refletem e percebem a diferença de luta (esporte) e briga (violência).

A respeito da percepção dos alunos, o estudo desenvolvido por Ueno e Souza (2014) avaliou a percepção dos alunos sobre a relação existente entre esporte de "lutas" e violência após um período de desenvolvimento das "lutas" nas aulas. Os resultados evidenciaram que os alunos conseguiram perceber o distanciamento existente entre "lutas" e violência e, além disso, enfatizaram a melhora na percepção de valores éticos/estéticos como coragem, autoconhecimento e autoconfiança.

Nascimento e Almeida (2007) comentam sobre dois grandes problemas que podem ser os motivos da pouca influência e acei- 
O conteúdo lutas nas aulas de educação física em escolas do Oeste do Paranaense Andreia Cristine Becker • Gabriela Simone Harnisch • Gustavo André Borges

tação das atividades relacionada às "lutas" nas aulas de educação física, que seriam a falta de vivência pessoal em "lutas", por parte dos professores, e a questão da violência, que muitos julgam ser intrínseca às suas práticas, o que dificulta a possibilidade desse conteúdo ser introduzido na escola. Nessa mesma direção, Rufino e Darido (2015) advogam que o ensino das "lutas" é assegurado em termos de Diretrizes Curriculares Estaduais, mas costuma ser um conteúdo pouco abordado por muitos cursos de formação superior em licenciatura em Educação Física, o que faz com que haja problemas para a sua efetivação nas escolas.

Quando questionados sobre acreditarem que o conteúdo "lutas" proporciona algum benefício aos alunos, todos os professores afirmaram que sim, que acreditam que as "lutas" realmente proporcionam benefícios. Em relação à categoria benefícios, alguns afirmam que houve maior interesse dos alunos em praticar "lutas" em academias, "melhor conhecimento, sobre as "lutas"'" o professor número 4. O principal benefício proporcionado por esse conteúdo talvez tenha sido expresso pela maioria dos professores quando afirmam que "quando ele (aluno) começa a praticar, ele percebe que precisa ter esse respeito" o professor número 3; "respeito as regras" o professor número 5; e "questão do respeito, é bem desenvolvida" o professor número 7. Também foram citados, como benefícios, a "disciplina" e o "autocontrole", embora em menor proporção.

Os professores que não desenvolvem o conteúdo "lutas" em suas aulas foram questionados sobre quais são as dificuldades encontradas para isso. Nessa categoria, de maneira geral, foram relatadas, por exemplo, o fato de terem tido apenas o conteúdo de judô durante a formação acadêmica, portanto isso pode ter refletido na falta de conhecimento de como trabalhar esse conteúdo nas escolas. Também foram relatadas as questões estruturais da escola, tal como a falta do espaço físico e de materiais específicos. Houve também uma preocupação com a questão da violência, que poderia ser estimulada nas aulas, portanto é uma justificativa para não se desenvolver esse conteúdo. Apesar de todos terem afirma- 
O conteúdo lutas nas aulas de educação física em escolas do Oeste do Paranaense Andreia Cristine Becker • Gabriela Simone Harnisch • Gustavo André Borges

do que o conteúdo é importante e eles terem tido a disciplina de judô na formação acadêmica, as respostas denotaram que ela não foi suficiente para desenvolverem esse conteúdo nas escolas.

A partir das respostas, é possível perceber a insegurança que eles possuem em trabalhar com um assunto no qual eles não possuem domínio. Sendo assim, observamos que são as mesmas alegações que já se encontram na literatura. Por exemplo, para Boehl et al. (2018), não ter a experiência prática em artes marciais, uma formação em nível superior precária, a falta de materiais e a questão do espaço na escola, o pouco conhecimento, entre outras, são justificativas também apresentadas pelos professores em seu estudo.

Ainda segundo Boehl et al. (2018), dúvidas e insegurança são questões que surgem em relação ao desenvolvimento das "lutas" como unidade temática na educação física escolar. Quando demonstrado desconhecimento referente ao conteúdo, ocorrem interferências com a ideia de que desenvolver "lutas" nas escolas pode tornar os alunos mais violentos e agressivos.

Ainda existe uma falta de compreensão entre o que é "luta" e o que é "briga", ainda não foram identificadas as suas diferenças e ambas são jogadas em vala comum. Por esses motivos, muitas vezes os professores que não possuem conhecimento e muito menos afinidade com a prática das "lutas", e tampouco conhecem a filosofia, se sentem impedidos, incapazes de realizar o conteúdo de "lutas" em suas aulas (BOEHL et al., 2018).

Ainda a respeito da questão da violência, Hobold (2018) defende que as "lutas", quando trabalhadas de forma correta, auxiliam no combate à violência e indisciplina, dentre outros. Contudo, ainda é difícil saber quem são os profissionais qualificados para ministrarem esse conteúdo, pois a maioria deles não tem formação em ensino superior de forma adequada. Ou seja, para aqueles professores que tiveram uma sólida formação extracurricular nas artes marciais, como o judô ou caratê, as suas aulas podem ate- 
O conteúdo lutas nas aulas de educação física em escolas do Oeste do Paranaense Andreia Cristine Becker • Gabriela Simone Harnisch • Gustavo André Borges

nuar os casos mais graves de indisciplina ou de violência entre os seus alunos.

No presente estudo, quando os professores foram questionados sobre pretenderem trabalhar o conteúdo de "lutas" durante as suas aulas em outra oportunidade, apenas um deles assumiu que não trabalhará com esse conteúdo em suas aulas, mas as suas razões não foram explicadas. Para os demais, as respostas como "quem sabe, não vou dizer que não, mas quem sabe" o professor número 6. ou "no nono ano é bem interessante a gente poder trabalhar" o professor número 8 , demonstraram que há uma preocupação deles em desenvolver esse conteúdo em suas aulas.

Nessa perspectiva, em relação às possíveis metodologias ou estratégias que os professores pretendem utilizar, um deles afirmou que realizaria apenas aula teórica e aproveitaria o conhecimento de um profissional da área, enquanto outro diz que realizaria capacitações sobre o tema para conhecer as metodologias de ensino para esse fim. É possível perceber, através de pesquisas já realizadas na área de "lutas", na educação física escolar, que o problema se repete em vários locais, ou seja, o ensino do conteúdo de "lutas" não é ministrado ou, mesmo quando ministrado, ocorre de forma que não seja pedagogicamente adequado.

É evidente que existam dificuldades para a prática das aulas nas escolas, tanto nas pesquisas já existentes quanto nesta realizada na microrregião do Oeste do Paraná. Porém, essas “dificuldades" não devem ser desculpas para não se aplicar o conteúdo "lutas" nas aulas de Educação Física. É preciso que os professores busquem novos conhecimentos, através de capacitações, ou até com o auxílio de profissionais do esporte. Em relação à escola não oferecer condições físicas e materiais adequadas, é importante ressaltar que o professor poderá realizar suas aulas sem necessariamente estar ensinando alguma arte marcial, oferecendo, por exemplo, atividades lúdicas de jogos de força a curta distância e outras brincadeiras que envolvam materiais alternativos de combate para a média e a longa distância, como recomenda a BNCC. 
O conteúdo lutas nas aulas de educação física em escolas do Oeste do Paranaense Andreia Cristine Becker • Gabriela Simone Harnisch • Gustavo André Borges

Certamente os professores não devem ficar a vida inteira improvisando ou até mesmo postergando o ensino das "lutas" pela falta de condições ideais para as aulas. Segundo Carreiro (2011), é importante que as aulas tenham sempre boas condições e materiais, porém o que não é desejável é que os professores se sintam incapazes de realizar determinados temas por esses motivos e fiquem sempre esperando as melhores condições, sendo dependentes delas.

Alencar et al. (2015) observaram que a formação acadêmica pode ser um fator restritivo na prática pedagógica dos professores e, consequentemente, um fator muito preocupante para a não utilização das "lutas" nas aulas de educação física. Segundo eles, são raros os cursos de Educação Física que possuem a disciplina de "lutas", o que acaba ocasionando um distanciamento dos professores nessa área, provocando até mesmo uma grande resistência ao desenvolvimento desse conteúdo após formados.

A escola, portanto, é um local destinado ao conhecimento e é preciso que seja oportunizada aos alunos uma vivência das "lutas", buscando, assim, proporcionar-lhes o desenvolvimento físico, como moral e crítico, o respeito entre eles e respeito às regras, para que haja uma boa convivência tanto na aula como em qualquer lugar (CAMARGO et al., 2013).

\section{Conclusão}

Podemos afirmar que todos os professores que participaram da pesquisa consideram o conteúdo de "lutas" importante, porém apenas cinco deles o desenvolvem em suas aulas; os maiores benefícios relatados estão relacionados ao "respeito" entre os alunos e ao fato destes compreendem a diferença entre "lutas", enquanto conteúdo, ou seja, esporte de combate, e a manifestação de briga (violência). Tratando-se das práticas pedagógicas, constatou-se que os professores utilizam diversas estratégias, dentre elas se destacam as aulas teóricas (geralmente trabalhos escritos com 
O conteúdo lutas nas aulas de educação física em escolas do Oeste do Paranaense Andreia Cristine Becker • Gabriela Simone Harnisch • Gustavo André Borges

os alunos) ou eventualmente com aulas ministradas por profissionais de alguma determinada modalidade específica, o que vai ao encontro da literatura, a qual enfatiza o ensino das "lutas" a partir das aproximações, classificando-as em "lutas" de curta, média e longa distância.

Em relação aos fatores que dificultam o desenvolvimento das "lutas" nas aulas de educação física, ficou evidenciado que durante a formação acadêmica, apenas uma única disciplina de arte marcial acabou refletindo dificuldade em trabalhar esse conteúdo de forma mais ampla, como atualmente se recomenda, independentemente de a escola possuir espaço físico adequado ou de ter materiais específicos para esse fim. Quando desenvolvem as atividades de "lutas"/esportes de combate de forma adequada e com atividades práticas, os professores acabam por ensinar uma única modalidade de combate, limitada pela sua própria experiência com essa modalidade.

Com base nos resultados da pesquisa, conclui-se que o conteúdo "lutas" não é suficientemente desenvolvido nas aulas de educação física do ensino fundamental, nas escolas da microrregião do oeste paranaense, pois tem sido ministrado, na maioria das vezes, de forma teórica ou através de professores convidados. Outrossim, tendo como limitação um pequeno conjunto de professores de uma região específica do país, dificultando uma estrapolação dos resultados encontrados, recomendamos que outros estudos sobre a formação inicial e continuada sejam produzidos, buscando compreender de forma ainda mais ampla as dificuldades encontradas pelos professores sobre a inserção da temática "lutas" nas aulas de educação física.

\section{Referências}

ALENCAR, Y. O.; SILVA, L. H.; LAVOURA, T. N.; DRIGO, A. J. As "lutas" no ambiente escolar: uma proposta pedagógica. Revista 
O conteúdo lutas nas aulas de educação física em escolas do Oeste do Paranaense Andreia Cristine Becker • Gabriela Simone Harnisch • Gustavo André Borges

Brasileira de Ciência e Movimento, Brasília, v. 23, n. 3, p. 53-63, 2015.

BARDIN, L. Análise do conteúdo. Lisboa: Edições 70, 1995.

BOEHL, W. R.; LIMA, L. S.; FONSECA, D. G. (In)Justificativas e (im) possibilidades do professor de educação física em adotar as "lutas" como unidade temática. Caderno de Educação Física e Esporte, Marechal Cândido Rondon, v. 16, n. 1, p. 69-77, 2018.

BRASIL. Base Nacional Comum Curricular. Disponível em: http://basenacionalcomum.mec.gov.br/wp-content/ uploads/2018/02/bncc-20dez-site.pdf. Acesso em: 12 jul. 2018. BREDA, M.; GALATTI, L.; SCAGLIA, A. J.; PAES, R, R. Pedagogia do esporte aplicada às "lutas". São Paulo: Phorte, 2010.

CAMARGO, J. L.; MARCONDES, F.; GURALECKA, J. D. Metodologia do ensino do conteúdo de "lutas" de $5^{\mathrm{a}}$ a $8^{\mathrm{a}}$ série em escolas estaduais de Guarapuava - PR. Revista Guairacá, Guarapuava, v. 5, n. 2, p. 64-80, 2013.

CARREIRO, E. A. "Iutas". In: DARIDO, S. C.; RANGEL, I. C. A. Educação física na escola: Implicações para a prática pedagógica. 2. ed. Rio de Janeiro: Guanabara Koogan, 2011. p. 246-263. FERREIRA, H. S. As "lutas" na educação física escolar. Revista de Educação Física, Fortaleza, n. 135, p. 36-44, 2006.

FONSECA, J. M. C.; FRANCHINI, E.; DEL VECCHIO, F. B. Conhecimento declarativo de docentes sobre a prática de "lutas", artes marciais e modalidades esportivas de combate nas aulas de educação física escolar em pelotas, Rio Grande do Sul. Pensar a Prática, Goiânia, v. 16, n. 2, 2013.

GERHARDT, T. E.; SILVEIRA, D. T. (Org.). Métodos de pesquisa. Porto Alegre: UFRGS, 2009.

GOMES, M. S. P.; MORATO, M. P.; DUARTE, E.; ALMEIDA, J. J. G. Ensino das "lutas": dos princípios condicionais aos grupos situacionais. Movimento, Porto Alegre, v. 16, n. 2, p. 207-227, 2010. 
O conteúdo lutas nas aulas de educação física em escolas do Oeste do Paranaense Andreia Cristine Becker • Gabriela Simone Harnisch • Gustavo André Borges

HARNISCH, G. S.; WALTER, L. W.; GUILHERME, S. M. O.; SILVA. B. P.; LOTTERMANN, A. L. F.; BORELLA. D. R. As "lutas" na educação física escolar: um ensaio sobre os desafios para sua inserção. Caderno de Educação Física e Esporte, Marechal Cândido Rondon, v. 16, n. 1, 179-184, 2018.

HEGELE, B.; GONZÁLEZ, F. J.; BORGES, R. M. Possibilidade do ensino das "lutas" na escola: uma pesquisa-ação com professores de educação física. Caderno de Educação Física e Esporte, Marechal Cândido Rondon, v. 16, n. 1, p. 1-9, 2018.

HOBOLD, E. "lutas": desafios para a Educação Física e Esportes. Caderno de Educação Física e Esporte, Marechal Cândido Rondon, v. 16, n 1, p. 11-12, 2018.

LANÇANOVA, J. E. D. S. "lutas" na educação física escolar: alternativas pedagógicas, 2007. Disponível em: file:///D:/TCC/ LANÇANOVA\%202007.pdf. Acesso em: 05 nov. 2018.

MATOS, J. A. B.; HIRAMA, L. K.; GALATI, L.R.; MONTAGNER, P.C. A presença/ausência do conteúdo "lutas" na educação física escolar: identificando desafios e propondo sugestões. Conexões, Campinas, v. 13, n. 2, p. 117-135, 2015.

NASCIMENTO, P. R. B.; ALMEIDA, L. A tematização das "lutas" na Educação Física Escolar: restrições e possibilidades. Movimento, Porto Alegre, v. 13, n. 3, p. 91-110, 2007.

PARANÁ. Secretaria de Estado da Educação do Paraná. Diretrizes Curriculares da Educação Básica. Curitiba, 2008. Disponível em: file:///D:/TCC/Diretrizes\%20Curriculares\%20Educacao\%20 Fisica\%20-\%20Paraná\%202008.pdf. Acesso em: 25 maio 2018. RUFINO, L. G. B. As "lutas" no contexto escolar e outros ambientes educacionais. Revista Brasileira de Prescrição e Fisiologia do Exercício, São Paulo, v. 11, n. 63, p. 914- 916, 2016.

RUFINO, L. G. B.; DARIDO, S. 0 ensino das "lutas" na escola: possibilidades para a educação física. Porto Alegre: Penso, 2015b. RUFINO, L. G. B.; DARIDO, S. O ensino das "lutas" nas aulas de educação física: Análise da prática pedagógica à luz de especialis- 
O conteúdo lutas nas aulas de educação física em escolas do Oeste do Paranaense Andreia Cristine Becker • Gabriela Simone Harnisch • Gustavo André Borges

tas. Revista da Educação Física, Maringá, v. 26, n. 4, p. 505-518, 2015a.

RUFINO, L. G. "Iutas". In: GONZÁLEZ, F. J.; DARIDO, S. C.; OLIVEIRA, A. A. B. "lutas" capoeira e práticas corporais de aventura:

práticas corporais e a organização do conhecimento. Maringá: Eduem, 2014. p. 31-67.

SANTOS, M. A. R.; BRANDÃO, P. P. S. "lutas" e a formação de professores de educação física: reflexos na atuação profissional de docentes da rede municipal de educação de Belém - PA. Caderno de Educação Física e Esporte, Marechal Cândido Rondon, v. 16, n. 1, p. 1-9. 2018.

UENO, V. L. F.; SOUZA, M. F. Agressividade, violência e budo: temas da educação física em uma escola estadual de Goiânia. Pensar a Prática, Goiânia, v. 17, n. 4, p. 1-14, 2014.

\section{Publisher}

Universidade Federal de Goiás. Faculdade de Educação Física e Dança. Publicação no Portal de Periódicos UFG. As ideias expressadas neste artigo são de responsabilidade de seus autores, não representando, necessariamente, a opinião dos editores ou da universidade. 